TP Periodica Polytechnica Chemical Engineering

62(2), pp. 129-136, 2018

https://doi.org/10.3311/PPch.11228

Creative Commons Attribution (i)

RESEARCH ARTICLE

\section{Thermoplastic Starch/Wood Composites: Effect of Processing Technology, Interfacial Interactions and Particle Characteristics}

\author{
Erika Fekete ${ }^{1,2^{*}}$, Dávid Kun ${ }^{1,2}$, János Móczó ${ }^{1,2}$
}

Received 06 July 2017; accepted after revision 28 September 2017

\begin{abstract}
Thermoplastic starch (TPS)/wood composites in a wide composition range were prepared in an internal mixer followed by compression molding. Three types of lignocellulose fibers were used to study the effect of particle and surface characteristics on the processability as well as the mechanical and water absorption properties of the composites. The mechanical properties of these composites were also compared with those of the composites processed by injection molding in an earlier study, and the effect of processing technology on the mechanical properties was also investigated. The processing of TPS/ lignocellulose composites in the internal mixer demanded more energy with increasing amount and aspect ratio of the fibers as a result of a network formation. Only a small variation among the dispersion component of the surface tension of the wood samples was found, and almost no difference in the stiffness and strength of the composites prepared in the internal mixer was observed. The results proved that the influence of the processing method on the stiffness and strength of the composites depends strongly on the aspect ratio of the wood particles. Increasing anisotropy results in increasing difference in the mechanical properties of the composites prepared by different methods. The equilibrium water uptake of the fibers and the composites depended especially on the size and, consequently, on the specific surface area of the wood fibers.
\end{abstract}

\section{Keywords}

starch composites, particle characteristics, processing technology, mechanical properties, water uptake

\footnotetext{
${ }^{1}$ Institute of Materials and Environmental Chemistry, Research Centre for Natural Sciences, Hungarian Academy of Sciences,

H-1117 Budapest, Magyar tudósok körútja 2., Hungary

${ }^{2}$ Laboratory of Plastics and Rubber Technology,

Department of Physical Chemistry and Materials Science,

Budapest University of Technology and Economics,

H-1521 Budapest, P.O.B. 91, Hungary

"Corresponding author, e-mail: ebodine@mail.bme.hu
}

\section{Introduction}

Recently a growing interest has been shown in the application of biopolymers as packaging materials in order to reduce the environmental pollution caused by plastic waste and to achieve sustainable development. Starch is considered as one of the most promising biopolymers because it is readily available, cheap and biodegradable. Starch is a semicrystalline polymer and it represents the major form of stored carbohydrates in plants. Starch is a mixture of two substances composed of $\alpha$-D glucopyranosyl repeating units, an essentially linear polysaccharide-amylose and a highly branched polysaccharideamylopectin. One of the major problems with granular starch is its limited processability, which can be improved by the use of plasticizers. Thermoplastic starch can be obtained by the destruction of the starch granules in the presence of plasticizers under specific conditions. Polyols such as glycerol, glycols as well as water are the most widely used plasticizers [1-3]. The main disadvantages of TPS are its pronounced hydrophilic character and inadequate mechanical properties. The inferior properties of TPS can be improved by the incorporation of other materials (natural fibers, nanoclays, or other biodegradable polymers) [1, 2, 4-11].

A considerable number of papers deal with the effect of natural fibers on the properties of thermoplastic starch. Most of them study the influence of fiber type and amount usually by determining properties at one or two fiber contents. All kinds of fibers have been used as filler in TPS including various forms of cellulose [6, 12-24], jute [18, 25-27], sisal [28-33], wheat straw [13], flax [23, 34] hemp [13, 28, 35, 36], cotton [13, 37, 38], flax [19, 39], ramie [20, 40].

According to the existing literature a relatively small number of papers have been published which consider the practical relevance of TPS/wood composites [7, 41-46]. There are even fewer paper about systematic experiments carried out as a function of fiber content in a wide composition range $[2,41,42]$, furthermore, it is very difficult to find publications on the effect of processing methods on the properties of TPS/wood composites. In our earlier work we investigated different TPS/wood composites prepared by injection molding [47]. 
On the bases of the results we concluded that the modification of TPS with wood particles improves several properties considerably. Stiffness and strength increased, and the effect was stronger for fibers with larger aspect ratio. Wood fibers reinforced TPS considerably due to poor matrix properties and strong interfacial interactions, the latter resulting in decreased mobility of starch molecules and in the fracture of large wood particles during deformation. Strong interfacial adhesion led to smaller water absorption than predicted from the additive effect of the components, but water uptake remained relatively large even in the presence of wood particles. In the present study we investigate the effect of processing technology and the surface energy of fibers on the mechanical and water absorption properties.

\section{Experimental}

\subsection{Materials}

The corn starch used in the experiments was supplied by Hungrana Ltd. Hungary and its water content was $12 \%$. Glycerol with $0.5 \%$ water content was obtained from Molar Chemicals Ltd. Hungary and it was used without further purification or drying. Three different wood fibers used as reinforcement were obtained from Rettenmaier and Söhne $\mathrm{GmbH}$, Germany. The particle characteristics of the fibers are listed in Table 1. Composites were prepared with 5, 10, 15, 20, and $30 \mathrm{~V} / \mathrm{V} \%$ fiber content.

Table 1 Particle characteristics and the dispersion component of surface tension $\left(\gamma_{s}^{d}\right)$ of the studied fibers

\begin{tabular}{llll}
\hline Fiber & Arbocel CW 630 & Filtracel EFC 1000 & Arbocel FT 400 \\
\hline $\mathrm{D}[4,3]^{\mathrm{a}}(\mu \mathrm{m})$ & $39.6 \pm 1.0$ & $213.1 \pm 1.6$ & $171.2 \pm 2.5$ \\
Length $^{\mathrm{b}}(\mu \mathrm{m})$ & $93.49 \pm 6.0$ & $363.40 \pm 31.3$ & $235.24 \pm 25.1$ \\
Diameter $^{\mathrm{b}}(\mu \mathrm{m})$ & $33.25 \pm 3.2$ & $63.91 \pm 6.1$ & $21.80 \pm 1.7$ \\
Aspect ratio $^{\mathrm{b}}$ & $3.48 \pm 0.5$ & $6.84 \pm 0.9$ & $12.60 \pm 1.5$ \\
$\left(\gamma_{s}^{d}\right)^{\mathrm{c}}\left(\mathrm{mJ} / \mathrm{m}^{2}\right)$ & $38.4 \pm 0.5$ & $40.2 \pm 0.7$ & $45.1 \pm 0.3$ \\
\hline
\end{tabular}

a) volume average particle size

b) average values determined from scanning electron micrographs

c) measured by inverse gas chromatography

Both the corn starch and the lignocellulose fibers were dried in an oven before composite preparation $\left(100^{\circ} \mathrm{C}\right.$ for 24 hours and $105^{\circ} \mathrm{C}$ for 4 hours, respectively). Thermoplastic starch containing $36 \mathrm{~m} / \mathrm{m} \%$ glycerol was prepared by dry-blending in a Henschel FM/A10 high speed mixer at $2000 \mathrm{rpm}$. TPS pellets were produced by processing the dry-blend with a Rheomex 3/4" single screw extruder attached to a Haake Rheocord EU $10 \mathrm{~V}$ driving unit at $140-150-160{ }^{\circ} \mathrm{C}$ barrel and $170{ }^{\circ} \mathrm{C}$ die temperatures, and $60 \mathrm{rpm}$ screw speed. TPS pellets and fibers were homogenized in an internal mixer (Brabender W50 EH) at $150{ }^{\circ} \mathrm{C}$ for $10 \mathrm{~min}$ at $50 \mathrm{rpm} .1 \mathrm{~mm}$ thick plates were compression molded from the melt at $150{ }^{\circ} \mathrm{C}$ and for $5 \mathrm{~min}$. The composite samples were put in a desiccator in order to keep them in a dry atmosphere until the beginning of tensile testing and water absorption measurements.

\subsection{Methods}

The dispersion component of the surface tension $\left(\gamma_{s}^{d}\right)$ of the lignocellulose samples was determined by inverse gas chromatography (IGC) at infinite dilution using n-alkanes with different chain lengths. IGC measurements were carried out using a Perkin Elmer Autosystem XL apparatus, after conditioning the samples at $105^{\circ} \mathrm{C}$ for $16 \mathrm{~h}$ under a constant flow of nitrogen, at $40{ }^{\circ} \mathrm{C}$. A new column was prepared for each set of experiments. Vapor samples of 5-20 $\mu \mathrm{l}$ were injected into the column and retention peaks were recorded by a FID detector. Each reported value is the result of three parallel measurements. High-purity nitrogen was used as carrier gas and its flow rate changed between 5 and $20 \mathrm{ml} / \mathrm{min}$ depending on the type of adsorbent and adsorbate. The $\gamma_{s}^{d}$ values were calculated by the method of Dorris and Gray [48].

The mechanical properties of all the composites were characterized by tensile testing using an Instron 5566 universal testing machine with a setting of $5 \mathrm{~mm} / \mathrm{min}$ cross-head speed and $115 \mathrm{~mm}$ gauge length at $23{ }^{\circ} \mathrm{C}$ and $52 \%$ relative humidity (RH). Tensile tests were performed on five parallel specimens. The water absorption of the wood fibers and the composites prepared in the internal mixer was also determined at $23{ }^{\circ} \mathrm{C}$ and $52 \%$ relative humidity by the measurement of the weight increase of the specimens. The desired relative humidity was achieved with a saturated solution of $\mathrm{Mg}\left(\mathrm{NO}_{3}\right)_{2}$.

\section{Results and discussion}

It is well known that the properties of polymer composites strongly depend among others on the component properties and the interfacial interactions which is the function of surface energy. Comparing the characteristics of the applied fibers it is clear that their average size (as well as the specific surface area) and the aspect ratio are very different, but only a small difference in the surface energy could be measured (Table 1) in spite of that the surface of the applied lignocelluloses are very different from each other (FT 400 is bleached, EFC 1000 is dewaxed fiber, while the surface of CW 630 is covered with wax).

\subsection{The effect of the particle characteristics of the fibers on the processability of TPS composites}

The equilibrium torques recorded during the homogenization in the internal mixer are plotted against the composition for all TPS/wood composites in Fig. 1. According to the figure the processing of TPS/lignocellulose demands more energy with increasing fiber content and aspect ratio, respectively. Previous studies on wood reinforced composites have proved that aggregation rarely occurs, but fibers might touch each other and thus hinder their mobility, which stems purely from geometric reasons [49-52], and long fibers may even form a loose network $[53,54]$. 


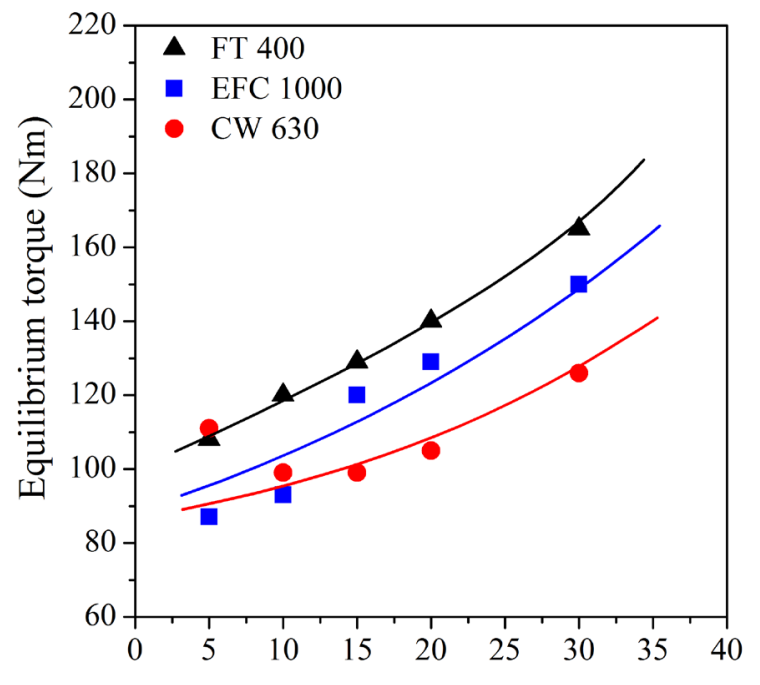

Fiber content $(\mathrm{V} / \mathrm{V} \%)$

Fig. 1 Equilibrium torque recorded during sample preparation as a function of fiber content

\subsection{The effect of fiber surface energy and processing technology on the mechanical properties of TPS composites}

Typical tensile stress-elongation curves are presented in Fig. 2. Similar traces were observed for all composites investigated indicating that filler characteristics has only a slight effect on the mechanical properties.

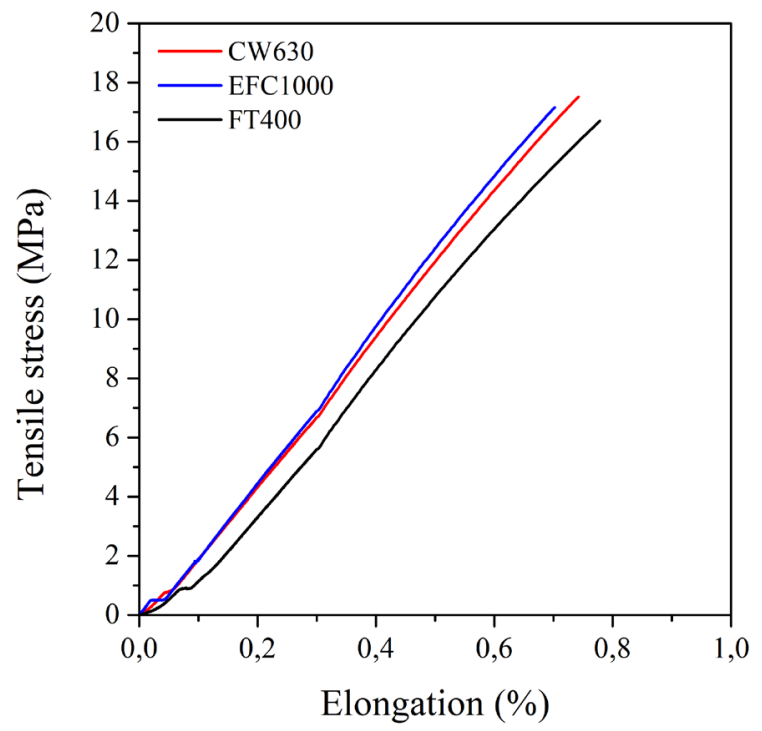

Fig. 2 Tensile stress- elongation curves of TPS/wood fiber composites, fiber content $20 \mathrm{~V} / \mathrm{V} \%$

Stiffness and strength are used the most frequently to estimate the effect of fillers and fibers on the properties of composites. The modulus, tensile strength and elongation at break of our TPS composites are plotted against fiber content in Fig. 3a-c, respectively.

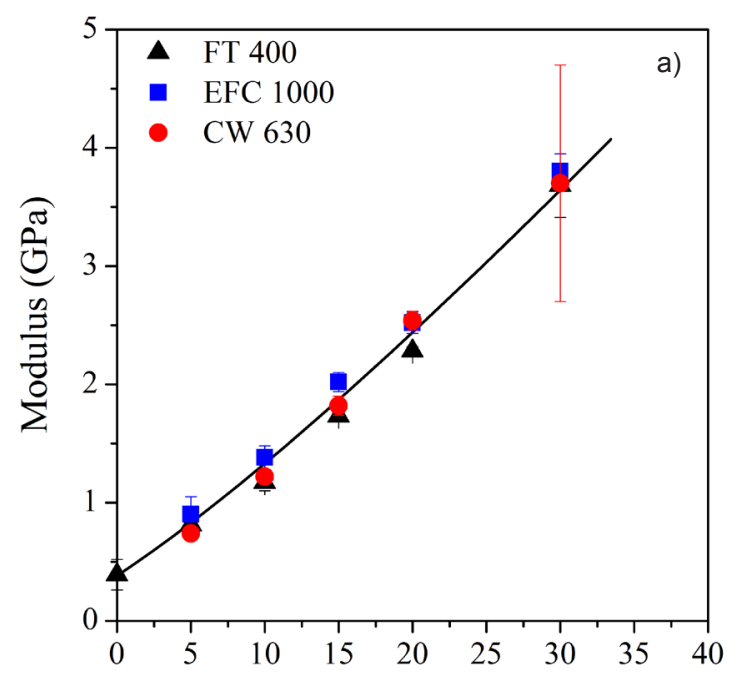

Fiber content $(\mathrm{V} / \mathrm{V} \%)$
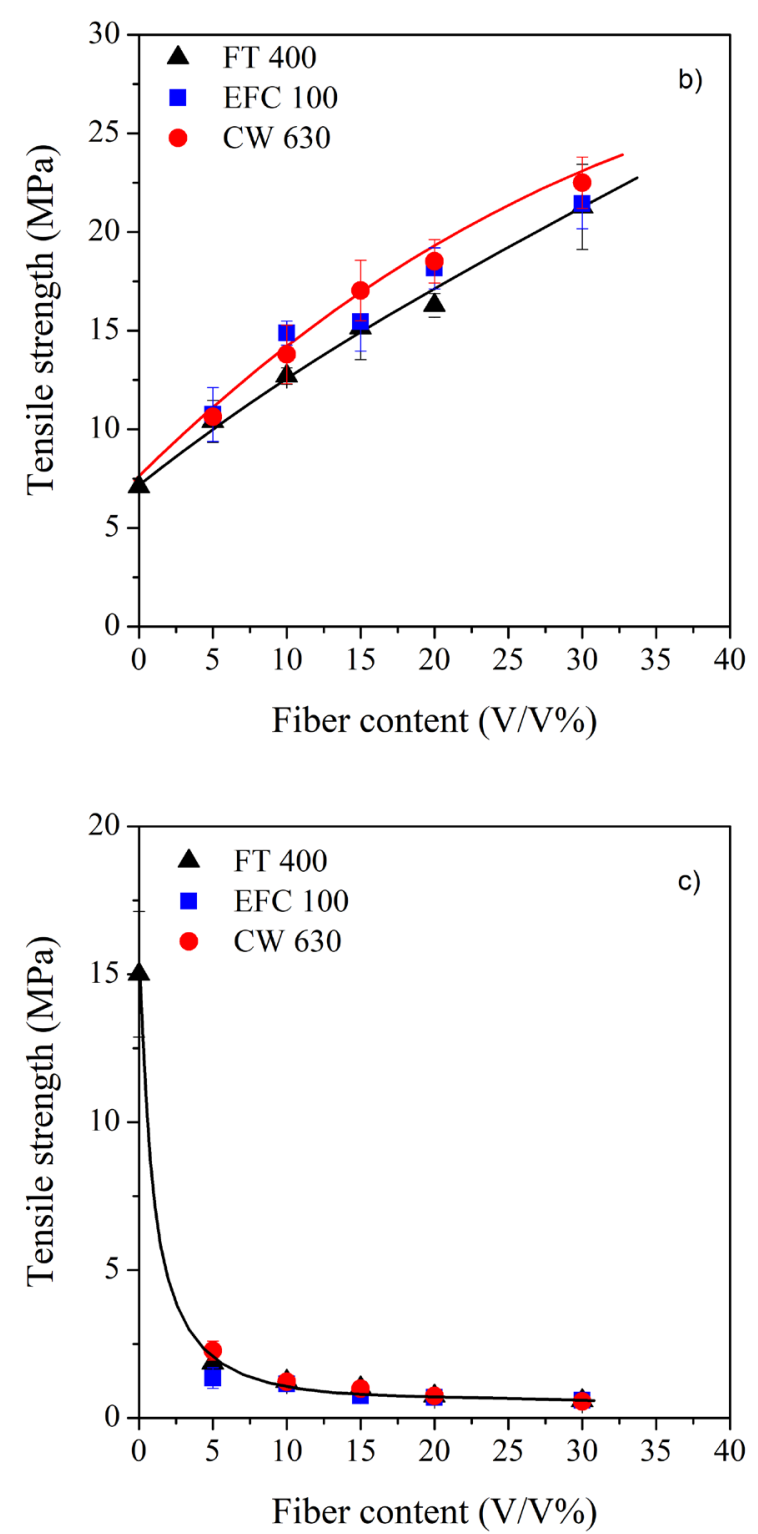

Fig. 3 Composition dependence of modulus (a), tensile strength (b) and elongation at break (c) of TPS composites prepared in internal mixer 
According to the Fig. 3a stiffness increases from around $0.38 \mathrm{GPa}$ up to approximately $3.8 \mathrm{GPa}$, while tensile strength from 7.5 MPa to $23 \mathrm{MPa}$, thus the modification of TPS with fibers results in very strong reinforcement. Although in our previous paper we proved that the reinforcing effect of wood fibers in TPS composites prepared by injection molding strongly depend on the aspect ratio of the fiber [47], the results of the present investigation did not show too much difference among the mechanical properties of the TPS composites containing fibers with different particle characteristics. The measured modulus and tensile strength values depend significantly on the fiber content, but not on the particle size and aspect ratio. The impact of the slightly dissimilar surface energies cannot be detected either.
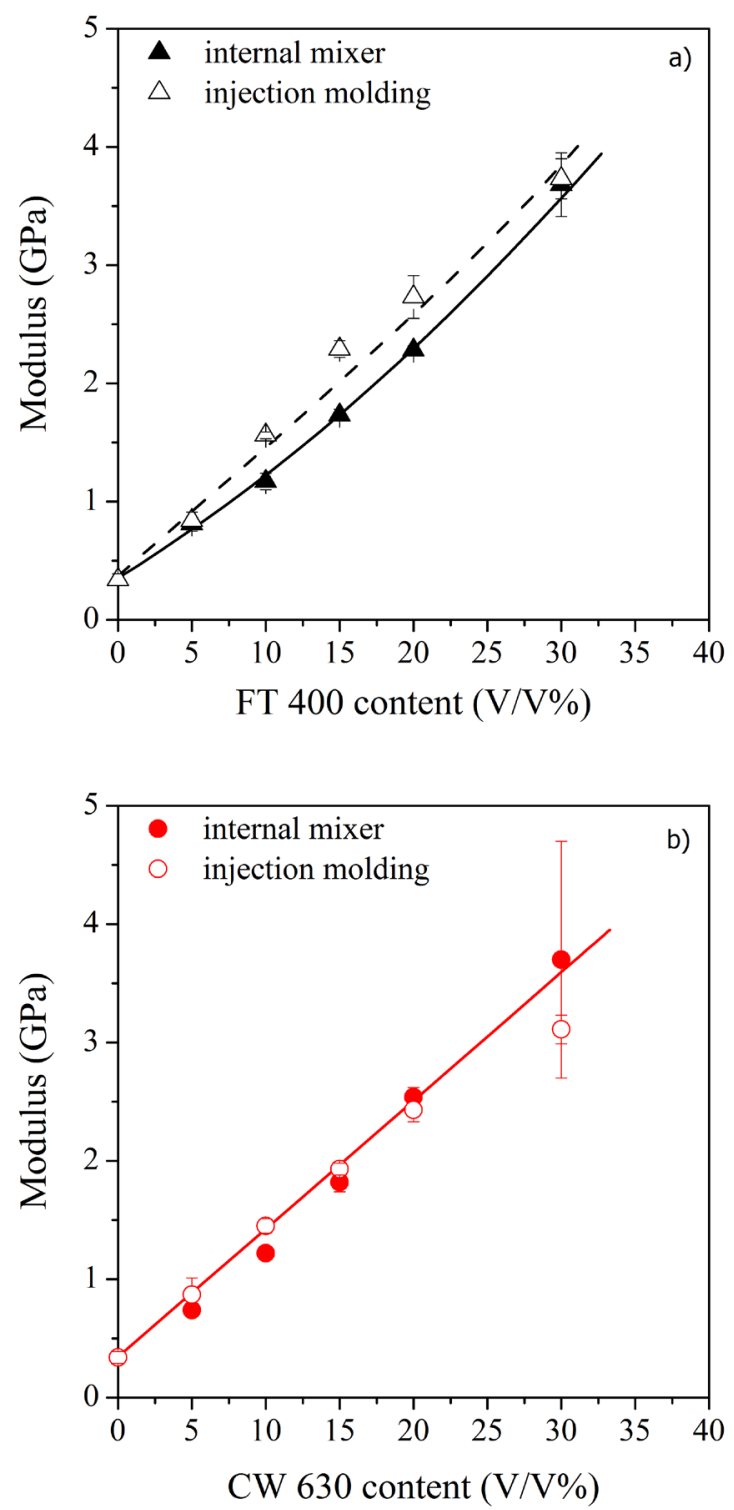

Fig. 4 Effect of the processing technology and fiber aspect ratio on the stiffness of TPS composites

It is well known that the orientation of the anisotropic particles results in a reinforcing effect in polymer composites, and a larger extent of orientation can be achieved by injection molding than with the sample preparation in the internal mixer, which cause lower extent of the fiber orientation. This can be well observed in Fig. 4 and Fig. 5 where the composition dependence of the mechanical properties of TPS/FT 400 and TPS/CW 630 are shown. The aspect ratio of FT 400 is 12.6 while that of CW 630 merely 3.5. It is clear from Fig. 4 and Fig. 5 that the reinforcing effect as well as the influence of the processing method is larger in the case of FT 400.
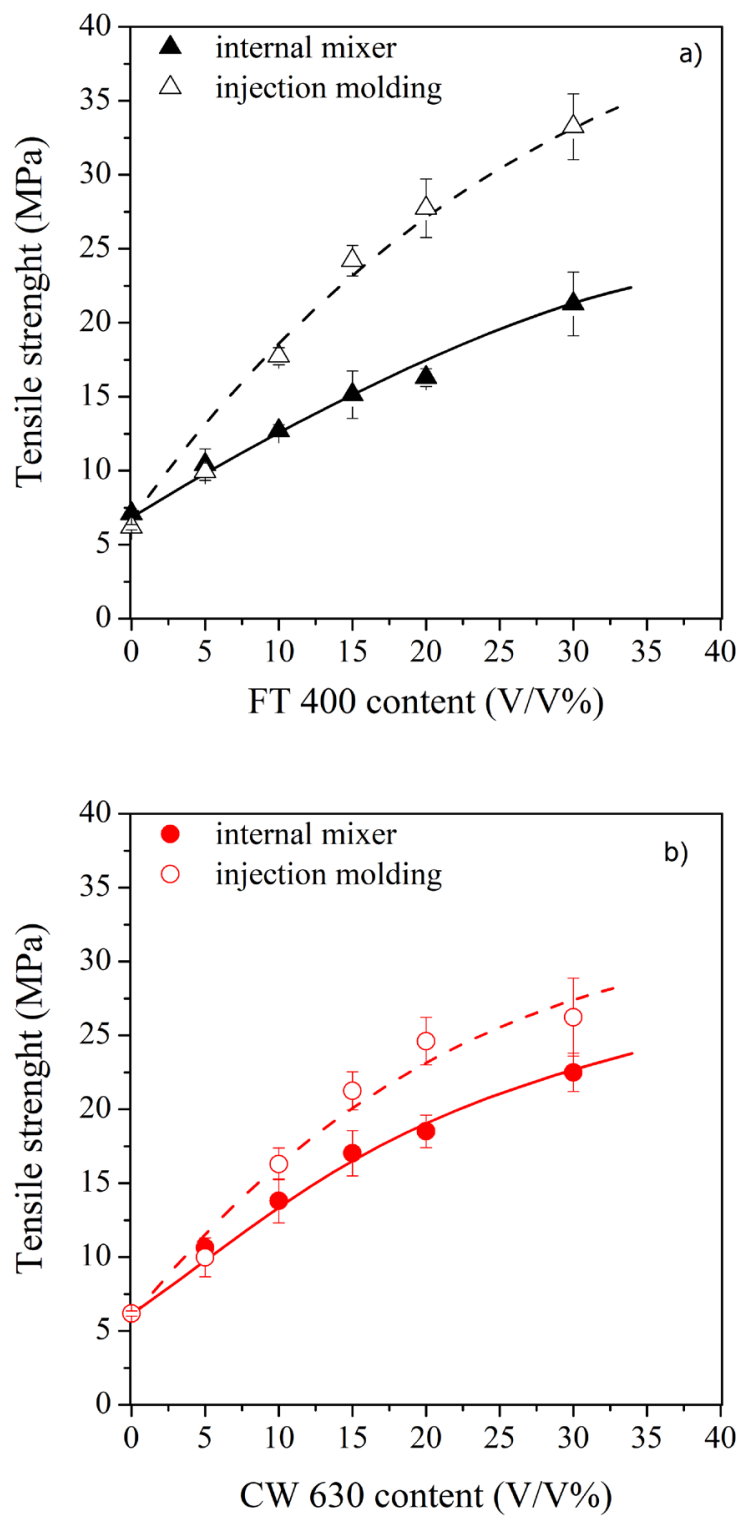

Fig. 5 Effect of the processing technology and fiber aspect ratio on the strength of TPS composites

\subsection{The effect of fiber properties on the water absorption of TPS composites}

As we mentioned earlier, one of the main disadvantages of TPS is its pronounced hydrophilic character. The absorption of excessive water weakens all the properties of TPS. Earlier studies showed that the reinforcement of TPS with natural fibers decreases its water uptake, therefore it results in the improvement of composite characteristics [12, 14, 15, 18, 40]. 
The water uptake of the fibers and TPS/FT 400 composites as a function of time is presented in Fig. 6 and Fig. 7, respectively. Equilibrium water absorption was determined from absorption isotherms by fitting the following form of Fick's law to the experimental results.

$$
M_{t}=M_{\infty}\left(1-\frac{8}{\pi^{2}}\left(\exp (-a t)+\frac{1}{9} \exp (-9)+\frac{1}{25} \exp (-25 a t)\right)\right)
$$

where $M_{t}$ is time dependent weight increase, $M_{\infty}$ the final (equilibrium) water uptake reached after infinite time, $t$ the time of absorption and $a$ a constant characterizing the overall rate of water absorption.

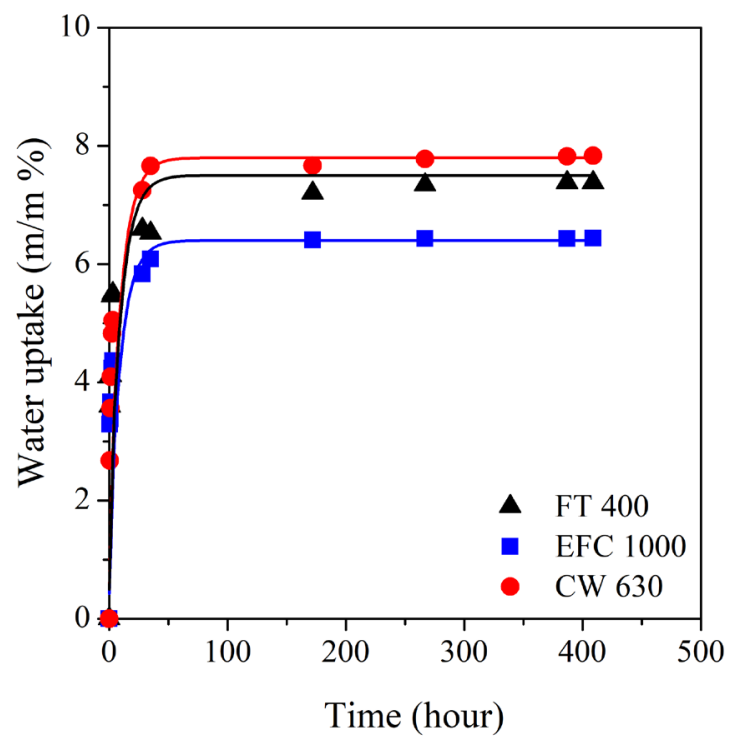

Fig. 6 Water uptake of wood fibers at $52 \% \mathrm{RH}$ relative humidity

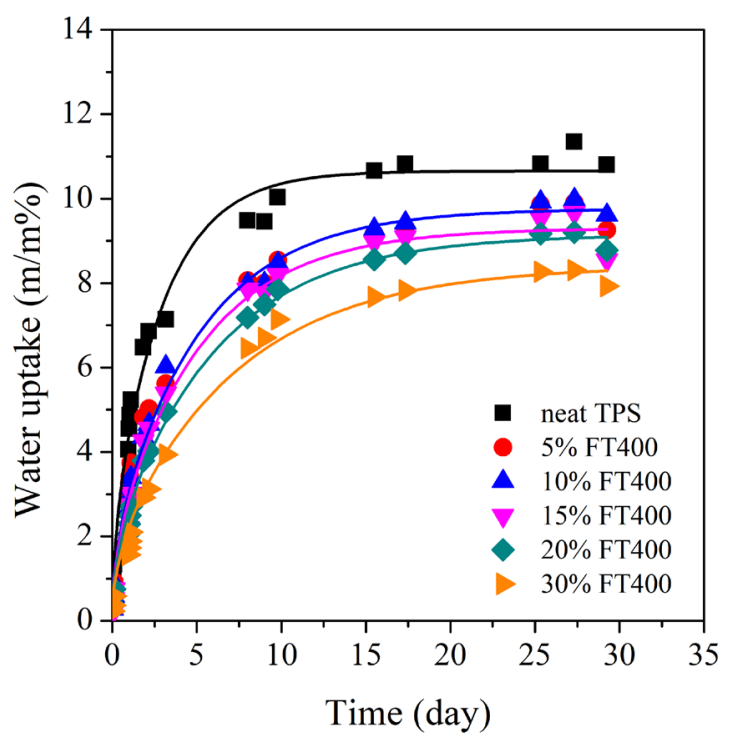

Fig. 7 Water uptake of TPS/FT 400 composites at $52 \%$ RH relative humidity
The equilibrium water uptake of the composites is plotted in Fig. 8 showing that water absorption decreases with fiber content, as reported in the literature [12,14,15,18,40]. Although the effect of the three fibers is very similar, it is clear from Fig. 8 that the smallest water uptake was measured on the TPS/EFC 1000 composites, while the largest on the TPS/CW 630 ones. Similar conclusions can be drawn from Fig. 6 too, since EFC adsorbs the smallest amount of water, CW630 in turn the largest. Comparing the properties of the fibers, it is evident that the surface energy of the fibers has no significant effect on water absorption capacity, but the particle size can influence it. CW 630, the fiber of the smallest particle size, ie. the largest specific surface area can adsorb the highest quantity of water. EFC 1000 has, however, the largest particles among the applied wood fibers and it adsorbs smaller amount of water than the other fibers.

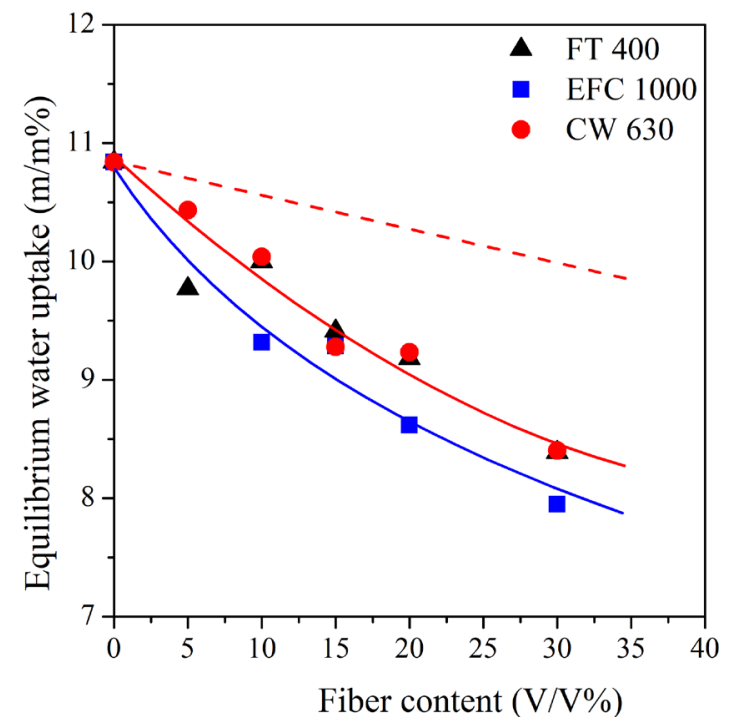

Fig. 8 Equilibrium water uptake of TPS/wood composites as a function of fiber content. The broken line indicates additivity between TPS and wood

\section{Conclusion}

Three types of wood fibers with different particle and surface characteristics were applied for the preparation of thermoplastic starch/wood composites in an internal mixer followed by compression molding. The processing of the composites in the internal mixer demanded more energy with the increasing amount and aspect ratio of the fillers because the wood fibers could hinder each other's mobility as a result of a network formation. For TPS/wood composites stiffness and strength did not depend on particle characteristics, and not even on surface energy. Formerly we proved that composite properties strongly depend on the polymer/filler interactions, but probably the variation of the surface energies of the applied fillers was not large enough to result in measurable differences. The mechanical properties of the composites prepared in the internal mixer were also compared with those of samples processed earlier by 
injection molding. The results proved that the influence of the processing method on the stiffness and strength of the composites depends strongly on the aspect ratio of the wood particles. As the extent of orientation of an anisotropic particle is much less during the homogenization in an internal mixer than during injection molding, the increasing anisotropy results in increasing difference in the mechanical properties of the composites prepared by different methods. Large differences were measured for TPS/FT 400 composites (largest aspect ratio), but only a minimal distinction for TPS/CW 630 ones (smallest aspect ratio). The particle characteristics of wood samples also have a strong effect on the water absorption ability of the composites. The equilibrium water uptake of fibers and composites depends especially on the size, consequently, on the specific surface area of the wood fibers.

\section{Acknowledgement}

The financial support of the National Scientific Research Fund of Hungary (OTKA Grant No. K 108934) is highly appreciated.

\section{References}

[1] Chivrac, F., Pollet, E., Averous, L. "Progress in nano-biocomposites based on polysaccharides and nanoclays." Materials Science and Engineering: R: Reports. 67(1), pp. 1-17. 2009.

https://doi.org/10.1016/j.mser.2009.09.002

[2] Averous, L. "Biodegradable multiphase systems based on plasticized starch: A review." Journal of Macromolecular Science, Part C. 44(3), pp. 231-274. 2004.

https://doi.org/10.1081/mc-200029326

[3] Avérous, L., Pollet, E. "Biodegradable Polymers." In: Avérous, L., Pollet, E. (eds.), Environmental Silicate Nano-Biocomposites. (pp. 13-39.), Springer London, 2012.

[4] Mitrus, M. "TPS and Its Nature, Thermoplastic Starch." Wiley-VCH Verlag GmbH \& Co. KGaA, 2010, pp. 77-104.

[5] Averous, L., Fringant, C., Moro, L. "Starch-based biodegradable materials suitable for thermoforming packaging." Starch-Starke. 53(8), pp. 368-371. 2001.

https://doi.org/10.1002/1521-379x(200108)53:8<368::aidstar368>3.0.co; $2-\mathrm{W}$

[6] Avérous, L., Fringant, C., Moro, L. "Plasticized starch-cellulose interactions in polysaccharide composites." Polymer. 42(15), pp. 6565-6572. 2001 .

https://doi.org/10.1016/S0032-3861(01)00125-2

[7] Avérous, L., Boquillon, N. "Biocomposites based on plasticized starch: thermal and mechanical behaviours." Carbohydrate Polymers. 56(2), pp. 111-122. 2004.

https://doi.org/10.1016/j.carbpol.2003.11.015

[8] Schwach, E., Averous, L. "Starch-based biodegradable blends: morphology and interface properties. Polymer International. 53(12), pp. 2115 2124. 2004 https://doi.org/10.1002/pi.1636

[9] Averous, L., Fringant, C. "Association between plasticized starch and polyesters: Processing and performances of injected biodegradable systems." Polym. Eng. Sci. 41(5), pp. 727-734. (2001).

https://doi.org/10.1002/pen.10768
[10] Vroman, I., Tighzert, L. "Biodegradable Polymers." Materials. 2(2), pp. 307-344. 2009

https://doi.org/10.3390/ma2020307

[11] Yixiang, X., Junjie, G., Milford, A. H. "Starch-Based Biodegradable Packaging." In: Encyclopedia of Agricultural, Food, and Biological Engineering. (pp. 1-4.), Taylor \& Francis, 2007.

[12] Ayadi, F., Dole, P. "Stoichiometric interpretation of thermoplastic starch water sorption and relation to mechanical behavior." Carbohydrate Polymers. 84(3), pp. 872-880. 2011.

https://doi.org/10.1016/j.carbpol.2010.12.024

[13] Benezet, J. C., Stanojlovic-Davidovic, A., Bergeret, A., Ferry, L., Crespy, A. "Mechanical and physical properties of expanded starch, reinforced by natural fibres." Industrial Crops and Products. 37(1), pp. 435-440. 2012. https://doi.org/10.1016/j.indcrop.2011.07.001

[14] Curvelo, A. A. S., de Carvalho, A. J. F., Agnelli, J. A. M. "Thermoplastic starch-cellulosic fibers composites: preliminary results." Carbohydrate Polymers. 45(2), pp. 183-188. 2001. https://doi.org/10.1016/S0144-8617(00)00314-3

[15] Ma, X. F., Yu, J. G., Kennedy, J. F. "Studies on the properties of natural fibers-reinforced thermoplastic starch composites." Carbohydrate Polymers. 62(1), pp. 19-24. 2005.

https://doi.org/10.1016/j.carbpol.2005.07.015

[16] Martins, I. M. G., Magina, S. P., Oliveira, L., Freire, C. S. R., Silvestre, A. J. D., Neto, C. P., Gandini, A. "New biocomposites based on thermoplastic starch and bacterial cellulose." Composites Science and Technology. 69(13), pp. 2163-2168. 2009.

https://doi.org/10.1016/j.compscitech.2009.05.012

[17] Muller, C. M. O., Laurindo, J. B., Yamashita, F. "Effect of cellulose fibers on the crystallinity and mechanical properties of starch-based films at different relative humidity values." Carbohydrate Polymers. 77(2), pp. 293-299. 2009.

https://doi.org/10.1016/j.carbpol.2008.12.030

[18] Soykeabkaew, N., Laosat, N., Ngaokla, A., Yodsuwan, N., Tunkasiri, T. "Reinforcing potential of micro- and nano-sized fibers in the starchbased biocomposites." Composites Science and Technology. 72(7), pp. 845-852. 2012.

https://doi.org/10.1016/j.compscitech.2012.02.015

[19] Soykeabkaew, N., Supaphol, P., Rujiravanit, R. "Preparation and characterization of jute- and flax-reinforced starch-based composite foams." Carbohydrate Polymers. 58(1), pp. 53-63. 2004. https://doi.org/10.1016/j.carbpol.2004.06.037

[20] Sreekala, M. S., Goda, K., Devi, P. V. "Sorption characteristics of water, oil and diesel in cellulose nanofiber reinforced corn starch resin/ramie fabric composites." Composite Interfaces. 15(2-3), pp. 281-299. 2008. https://doi.org/10.1163/156855408783810812

[21] Drakopoulos, S. X., Karger-Kocsis, J., Kmetty, Á., Lendvai, L., Psarras, G. C. "Thermoplastic starch modified with microfibrillated cellulose and natural rubber latex: A broadband dielectric spectroscopy study." Carbohydrate Polymers. 157, pp. 711-718. 2017.

https://doi.org/10.1016/j.carbpol.2016.10.036

[22] Montero, B., Rico, M., Rodríguez-Llamazares, S., Barral, L., Bouza, R. "Effect of nanocellulose as a filler on biodegradable thermoplastic starch films from tuber, cereal and legume." Carbohydrate Polymers. 157, pp. 1094-1104. 2017.

https://doi.org/10.1016/j.carbpol.2016.10.073

[23] Battegazzore, D., Bocchini, S., Frache, A. "Thermomechanical improvement of glycerol plasticized maize starch with high loading of cellulose, flax and talc fillers." Polymer International. 65(8), pp. 955-962. 2016. https://doi.org/10.1002/pi.5129 
[24] Lendvai, L., Karger-Kocsis, J., Kmetty, A., Drakopoulos, S. X. "Production and characterization of microfibrillated cellulose-reinforced thermoplastic starch composites." Journal of Applied Polymer Science. 133(2), 42397, 2016. https://doi.org/10.1002/app.42397

[25] Torres, F. G., Arroyo, O. H., Gomez, C. "Processing and mechanical properties of natural fiber reinforced thermoplastic starch biocomposites." Journal of Thermoplastic Composite Materials. 20(2), pp. 207-223. 2007. https://doi.org/10.1177/0892705707073945

[26] Wollerdorfer, M., Bader, H. "Influence of natural fibres on the mechanical properties of biodegradable polymers." Industrial Crops and Products. 8(2), pp. 105-112. 1998. https://doi.org/10.1016/S0926-6690(97)10015-2

[27] Wang, P., Chen, F., Zhang, H., Meng, W., Sun, Y., Liu, C. "Large-scale preparation of jute-fiber-reinforced starch-based composites with high mechanical strength and optimized biodegradability." Starch - Stärke. 69(11-12), pp. n/a. 2017.

https://doi.org/10.1002/star.201700052

[28] Girones, J., Lopez, J. P., Mutje, P., Carvalho, A. J. F., Curvelo, A. A. S., Vilaseca, F. "Natural fiber-reinforced thermoplastic starch composites obtained by melt processing." Composites Science and Technology. 72(7), pp. 858-863. 2012. https://doi.org/10.1016/j.compscitech.2012.02.019

[29] Sreekumar, P. A., Gopalakrishnan, P., Leblanc, N., Saiter, J. M. "Effect of glycerol and short sisal fibers on the viscoelastic behavior of wheat flour based thermoplastic." Composites Part A: Applied Science and Manufacturing. 41(8), pp. 991-996. 2010.

https://doi.org/10.1016/j.compositesa.2010.04.003

[30] Sreekumar, P. A., Leblanc, N., Saiter, J. M. "Characterization of bulk agro-green composites: Sisal fiber reinforced wheat flour thermoplastics." Polymer Composites. 31(6), pp. 939-945. 2010.

https://doi.org/10.1002/pc.20877

[31] Wang, G., Thompson, M. R., Liu, Q. "Controlling the moisture absorption capacity in a fiber-reinforced thermoplastic starch using sodium trimetaphosphate." Industrial Crops and Products. 36(1), pp. 299-303. 2012.

https://doi.org/10.1016/j.indcrop.2011.10.015

[32] Wang, C.-Z., Li, F.-Y., Wang, L.-M., Li, J.-F., Guo, A.-F., Zhang, C.-W., Liu, P. "Research on thermoplastic starch and different fiber reinforced biomass composites." RSC Advances. 5(62), pp. 49824-49830. 2015. https://doi.org/10.1039/C5RA08278A

[33] Campos, A., Teodoro, K. B. R., Teixeira, E. M., Corrêa, A. C., Marconcini, J. M., Wood, D. F., Williams, T. G., Mattoso, L. H. C. "Properties of thermoplastic starch and TPS/polycaprolactone blend reinforced with sisal whiskers using extrusion processing." Polymer Engineering \& Science. 53(4), pp. 800-808. 2013. https://doi.org/10.1002/pen.23324

[34] Bocz, K., Szolnoki, B., Wladyka-Przybylak, M., Bujnowicz, K., Harakaly, G., Bodzay, B., Zimonyi, E., Toldy, A., Marosi, G. "Flame retardancy of biocomposites based on thermoplastic starch." Polimery. 58(5), pp. 385-394. 2013. https://doi.org/10.14314/polimery.2013.385

[35] Kunanopparat, T., Menut, P., Morel, M. H., Guilbert, S. "Reinforcement of plasticized wheat gluten with natural fibers: From mechanical improvement to deplasticizing effect." Composites Part A: Applied Science and Manufacturing. 39(5), pp. 777-785. 2008.

https://doi.org/10.1016/j.compositesa.2008.02.001
[36] Ochi, S. "Development of high strength biodegradable composites using Manila hemp fiber and starch-based biodegradable resin." Composites Part A: Applied Science and Manufacturing. 37(11), pp. 1879-1883. 2006.

https://doi.org/10.1016/j.compositesa.2005.12.019

[37] Moriana, R., Karlsson, S., Ribes-Greus, A. "Assessing the Influence of Cotton Fibers on the Degradation in Soil of a Thermoplastic StarchBased Biopolymer." Polymer Composites. 31(12), pp. 2102-2111. 2010. https://doi.org/10.1002/pc.21007

[38] Prachayawarakorn, J., Sangnitidej, P., Boonpasith, P. "Properties of thermoplastic rice starch composites reinforced by cotton or low-density polyethylene." Carbohydrate Polymers. 81(2), pp. 425-433. 2010. https://doi.org/10.1016/j.carbpol.2010.02.041

[39] Saiah, R., Sreekumar, P. A., Gopalakrishnan, R., Leblanc, N., Gattin, R., Saiter, J. M. "Fabrication and characterization of $100 \%$ green composite: Thermoplastic based on wheat flour reinforced by flax fibers." Polymer Composites. 30(11), pp. 1595-1600. 2009. https://doi.org/10.1002/pc.20732

[40] Lu, Y. S., Weng, L. H., Cao, X. D. "Morphological, thermal and mechanical properties of ramie crystallites - reinforced plasticized starch biocomposites." Carbohydrate Polymers. 63(2), pp. 198-204. 2006. https://doi.org/10.1016/j.carbpol.2005.08.027

[41] Abbott, A. P., Palazuela Conde, J., Davis, S. J., Wise, W. R. "Starch as a replacement for urea-formaldehyde in medium density fibreboard." Green Chemistry. 14(11), pp. 3067-3070. 2012. https://doi.org/10.1039/c2gc36194a

[42] Agnantopoulou, E., Tserki, V., Marras, S., Philippou, J., Panayiotou, C. "Development of biodegradable composites based on wood waste flour and thermoplastic starch." Journal of Applied Polymer Science. 126(S1), pp. E273-E281. 2012.

https://doi.org/10.1002/app.35420

[43] Chakraborty, A., Sain, M., Kortschot, M., Cutler, S. "Dispersion of wood microfibers in a matrix of thermoplastic starch and starch-polylactic acid blend." Journal of Biobased Materials and Bioenergy. 1(1), pp. 71-77. 2007.

https://doi.org/10.1166/jbmb.2007.008

[44] Kuciel, S., Liber-Knec, A. "Biocomposites on the Base of Thermoplastic Starch Filled by Wood and Kenaf Fiber." Journal of Biobased Materials and Bioenergy. 3(3), pp. 269-274. 2009.

https://doi.org/10.1166/jbmb.2009.1026

[45] Kuciel, S., Kúzniar, P., Mikula, J., Liber-Knéc, A. "Mineral Microparticles and Wood Flour as Fillers of Different Biocomposites." Journal of Biobased Materials and Bioenergy. 6(4), pp. 475-480. 2012. https://doi.org/10.1166/jbmb.2012.1246

[46] Hietala, M., Rollo, P., Kekalainen, K., Oksman, K. "Extrusion Processing of Green Biocomposites: Compounding, Fibrillation Efficiency, and Fiber Dispersion." Journal of Applied Polymer Science. 131(6), 2014. https://doi.org/10.1002/app.39981

[47] Müller, P., Renner, K., Móczó, J., Fekete, E., Pukánszky, B. "Thermoplastic starch/wood composites: Interfacial interactions and functional properties." Carbohydrate Polymers. 102(1), pp. 821-829. 2014. https://doi.org/10.1016/j.carbpol.2013.10.083

[48] Dorris, G. M., Gray, D. G. "Adsorption of Normal-Alkanes at Zero Surface Coverage on Cellulose Paper and Wood Fibers." Journal of Colloid and Interface Science. 77(2), pp. 353-362. 1980. https://doi.org/10.1016/0021-9797(80)90304-5 
[49] Dányádi, L., Móczó, J., Pukánszky, B. "Effect of various surface modifications of wood flour on the properties of PP/wood composites." Composites Part A: Applied Science and Manufacturing. 41(2), pp. 199-206. 2010. https://doi.org/10.1016/j.compositesa.2009.10.008

[50] Dányádi, L., Renner, K., Móczó, J., Pukánszky, B. "Wood flour filled polypropylene composites: Interfacial adhesion and micromechanical deformations." Polymer Engineering \& Science. 47(8), pp. 1246-1255. 2007. https://doi.org/10.1002/pen.20768

[51] Renner, K., Kenyó, C., Móczó, J., Pukánszky, B. "Micromechanical deformation processes in PP/wood composites: Particle characteristics, adhesion, mechanisms." Composites Part A: Applied Science and Manufacturing. 41(11), pp. 1653-1661. 2010.

https://doi.org/10.1016/j.compositesa.2010.08.001

[52] Renner, K., Móczó, J., Pukánszky, B. "Deformation and failure of PP composites reinforced with lignocellulosic fibers: Effect of inherent strength of the particles." Composites Science and Technology. 69(10), pp. 1653-1659. 2009.

https://doi.org/10.1016/j.compscitech.2009.03.015
[53] Faludi, G., Hári, J., Renner, K., Móczó, J., Pukánszky, B. "Fiber association and network formation in PLA/lignocellulosic fiber composites." Composites Science and Technology. 77, pp. 67-73. 2013. https://doi.org/10.1016/j.compscitech.2013.01.006

[54] Faludi, G., Dora, G., Renner, K., Móczó, J., Pukánszky, B. "Biocomposite from polylactic acid and lignocellulosic fibers: Structure-property correlations." Carbohydrate Polymers. 92(2), pp. 1767-1775. 2013. https://doi.org/10.1016/j.carbpol.2012.11.006 